\title{
Evodiamine induces apoptosis and inhibits metastasis in MDA-MB-231 human breast cancer cells in vitro and in vivo
}

\author{
JIA DU* ${ }^{*}$ XIU-FENG WANG ${ }^{*}$, QIAN-MEI ZHOU, TIAN-LING ZHANG, YI-YU LU, HUI ZHANG and SHI-BING SU \\ Research Center for Traditional Chinese Medicine Complexity System, Shanghai University \\ of Traditional Chinese Medicine, Pudong, Shanghai 201203, P.R. China
}

Received January 23, 2013; Accepted April 16, 2013

DOI: 10.3892/or.2013.2498

\begin{abstract}
Breast cancer remains the leading cause of cancerrelated deaths among women. Owing to high efficiency and low toxic effects, further exploration of natural compounds from Chinese herbal medicine may be an efficient approach for breast cancer drug discovery. In this study, we investigated the effects of evodiamine on the growth and metastasis of MDA-MB-231 human breast cancer cells in vitro and in vivo. In vitro, evodiamine inhibited cell migration and invasion abilities through downregulation of MMP-9, urokinase-type plasminogen activator (uPA) and UPAR expression. Evodiamine-induced G0/G1 arrest and apoptosis were associated with a decrease in Bcl-2, cyclin D1 and cyclin-dependent kinase 6 (CDK6) expression and an increase in Bax and $\mathrm{p} 27^{\mathrm{Kip} 1}$ expression. Moreover, evodiamine regulated p-ERK and p-p38 MAPK expression. Evodiamine-induced apoptosis was enhanced by its combination with the extracellular signal-regulated kinase (ERK) inhibitor PD98059 or the p38 mitogen-activated protein kinase (p38 MAPK) inhibitor SB203580. Evodiamineinhibited metastasis was partly blocked by combination with PD98059 or SB203580. In vivo, the administration of evodiamine $(10 \mathrm{mg} / \mathrm{kg})$ significantly reduced tumor growth and pulmonary metastasis. These results demonstrate that evodiamine possesses antitumor activities via inhibition of cell migration and invasion, arrest of the cell cycle and induction of cell apoptosis in MDA-MB-231 cells.
\end{abstract}

\section{Introduction}

Breast cancer is the most frequently diagnosed cancer and the leading cause of cancer-related death among females world-

Correspondence to: Professor Shi-Bing Su, Research Center for Traditional Chinese Medicine Complexity System, Shanghai University of Traditional Chinese Medicine, 1200 Cailun Road, Pudong, Shanghai 201203, P.R. China

E-mail: shibingsu07@163.com

${ }^{*}$ Contributed equally

Key words: evodiamine, breast cancer, MDA-MB-231 cells, metastasis, cell cycle, apoptosis wide, accounting for $23 \%$ of the total new cancer cases and $14 \%$ of the total cancer deaths (1). The main causes of death of patients with breast cancer are due to the excessive proliferation and metastasis of cancer cells $(2,3)$. To date, various anticancer agents which are natural products derived from plants, have been used clinically as first-line option drugs, such as paclitaxel, camptothecins and vinorelbine (4-6). However, there is still the need for more effective drugs with low toxic effects for breast cancer therapy. Hence, it is a challenge to discover an agent that can efficiently suppress the abnormal growth and metastatic progression of breast cancer cells.

Evodiamine, a quinolone alkaloid, is a bioactive component isolated from the fruit of Evodia rutaecarpa, which is extracted from medicinal plants such as Evodia rutaecarpa (Juss.) Benth, Evodia rutaecarpa (Juss.) Benth. var. officinalis (Dode) Huang and Evodia rutaecarpa (Juss.) Benth. var. bodinieri (Dode) Huang. Evodiamine has been shown to exhibit comprehensive pharmacological activities including antiobesity, anti-IAV, protection against myocardial ischemia-reperfusion injury and regulation of testosterone secretion (7-10); and particularly, its anticancer bioactivity is indispensable.

Evodiamine arrests cancer cell cycle distributions and induces cell apoptosis to play a role in antitumor growth. Previous studies have indicated that evodiamine-induced S phase arrest in LoVo cells is associated with a marked decrease in the protein expression of cyclin A, cyclin A-dependent kinase 2 and cdc25c (11). Evodiamine caused blockage of cells in the G2/M phase, accompanied by an increase in the protein expression of cyclin B1 and the phosphorylated form of p34(cdc2) (Thr 161) in prostate cancer LNCaP cells (12). Evodiamine inhibited the growth of thyroid cancer ARO cells, arrested the cells at the $\mathrm{M}$ phase, and induced apoptosis through inducing the activation of caspase-3, -8 and -9 , and the cleavage of polyADP-ribose polymerase (13). Moreover, evodiamine was found to increase the expression of Bax and p53, decreased the expression of Bcl-2, lowered the mitochondrial transmembrane potential and induced the activation of caspase-3 in colorectal carcinoma COLO-205 cells (14).

Previous studies have revealed that evodiamine and paclitaxel may be regarded as leading compounds for use as antimetastatic agents acting through the inhibition of colon cancer cell migration without cytotoxicity (15). Evodiamine concentration-dependently inhibited the invasion of Lewis lung carcinoma (LLC) and B16-F10 melanoma in addition 
to colon 26-L5 carcinoma (16). Pretreatment of tumor cells with evodiamine before inoculation into mice as well as administration into mice after tumor inoculation both caused reduction in lung metastasis formation (17). Evodiamine was found to be a highly potent inhibitor of $N F-\kappa B$ activation, and it abrogated both inducible and constitutive NF- $\kappa \mathrm{B}$ activation. NF- $\mathrm{BB}$-regulated gene products such as $\mathrm{c}-\mathrm{Myc}, \mathrm{COX}-2$, MMP-9, ICAM-1, MDR1, survivin and Bfl-1/A1 were all downregulated by evodiamine (18).

Research has revealed that evodiamine has potent anticancer effects on various types of cancer cells, yet the targets and underlying mechanisms of evodiamine-induced cytotoxic and anti-metastatic actions in highly metastatic human breast cancer MDA-MB-231 cells remain unclear. Therefore, in this study, we aimed to ascertain whether evodiamine induces apoptosis and inhibits migration and invasion in MDA-MB231 cells in vitro and in vivo.

\section{Materials and methods}

Drugs and reagents. The compound evodiamine was purchased from Shanghai Research and Development Centre for Standardization of Traditional Chinese Medicine (Shanghai, China), and dissolved in dimethyl sulfoxide (DMSO). Dulbecco's modified Eagle's medium (DMEM), trypsin, penicillin and streptomycin were purchased from Gibco-BRL (Grand Island, NY, USA). 3-(4, 5-Dimethylthiazol-2yl)-2, 5-diphenyltetrazolium bromide (MTT), DMSO, propidium iodide (PI), acridine orange (AO) and Matrigel were purchased from Sigma-Aldrich (St. Louis, MO, USA). Antibodies against Bcl-2, cyclin D1, p27 ${ }^{\mathrm{Kip} 1}$, CDK6, p38 MAPK, p-p38 MAPK, p-ERK, p-SAPK/JNK, SAPK/JNK and GAPDH were purchased from Cell Signaling Technology Inc. (Danvers, MA, USA). Bax and ERK were purchased from Abgent (Flanders Ct, San Diego, CA, USA). Urokinase-type plasminogen activator (UPA) and UPAR were purchased from Santa Cruz Biotechnology Inc. (Santa Cruz, CA, USA). MMP-2 and -9 were purchased from Abcam (Cambridge, UK). IRDye $^{\mathrm{TM}}$ fluorescence antibodies were obtained from LI-COR Biosciences (Lincoln, NE, USA). SB203580 and PD98059 were obtained from Biomol (Philadelphia, PA, USA).

Cell lines and culture conditions. The human breast cancer cell line MDA-MB-231 was purchased from the Cell Bank of the Type Culture Collection of the Chinese Academy of Sciences (Shanghai, China) and cultured in DMEM supplemented with $10 \%$ fetal bovine serum (FBS), $100 \mathrm{U} / \mathrm{ml}$ penicillin and $100 \mu \mathrm{g} / \mathrm{ml}$ streptomycin at $37^{\circ} \mathrm{C}$ in a humidified atmosphere of $5 \% \mathrm{CO}_{2}$.

MTT assay. Cell viability was measured by the MTT assay. MDA-MB-231 cells $\left(5 \times 10^{4} / \mathrm{ml}\right)$ were plated in 96 -well plates overnight, and then treated with various concentrations of evodiamine. After 24, 48, $72 \mathrm{~h}$ of drug exposure, $20 \mu \mathrm{l}$ of MTT $(5 \mathrm{mg} / \mathrm{ml})$ was added to incubate for $4 \mathrm{~h}$. Then $150 \mu \mathrm{l}$ DMSO was added to dissolve the formazan crystals. The optical density (OD) was detected at $490 \mathrm{~nm}$ by an ELISA plate reader (BioTek Instruments, Inc., Winooski, VT, USA). The percentage of cell survival was calculated as follows: Cell survival rate $(\%)=($ OD sample/OD control $) \times 100 \%$.
Wound healing assay. MDA-MB-231 cells (2x10 $/ \mathrm{ml})$ were seeded in a 6-well culture plate to form a confluent monolayer. The monolayer of cells was then scrape-wounded with a sterile micropipette tip to create a wound of constant $(\sim 1 \mathrm{~mm})$ width. After removal of the cellular debris with phosphate-buffered saline (PBS) twice, cells were treated with medium containing the indicated concentration of evodiamine at $37^{\circ} \mathrm{C}$. After incubation for $24 \mathrm{~h}, \mathrm{MDA}-\mathrm{MB}-231$ cells that had migrated to the wounded region were observed (x100 magnification).

Migration and invasion assays. Migration and invasion assays were performed in 8- $\mu \mathrm{m}$-diameter pore size Transwell chambers in 24-well plates (Corning Incorporated, Corning, NY, USA). For the cell invasion assay, the internal surface of each polycarbonate membrane was coated with Matrigel $(30 \mu \mathrm{g})$ for $30 \mathrm{~min}$ at $37^{\circ} \mathrm{C}$ for gel formation and then blocked with serumfree DMEM containing $0.2 \%$ bovine serum albumin (BSA). In brief, MDA-MB-231 cells $\left(5 \times 10^{5} / \mathrm{ml}\right)$ were seeded onto the upper chamber in $200 \mu \mathrm{l}$ of serum-free medium containing evodiamine at concentrations of $0,15,30,60 \mu \mathrm{M}$, respectively; the lower compartment of the chamber was filled with $600 \mu \mathrm{l}$ DMEM supplemented with $0.2 \%$ BSA and $10 \%$ FBS. After incubation for $24 \mathrm{~h}$ at $37^{\circ} \mathrm{C}$, the cells in the upper surface of the membrane were carefully removed with a cotton swab, and cells that had migrated or invaded to the lower surface of the membrane were fixed with methanol and stained with $0.1 \%$ crystal violet for $30 \mathrm{~min}$. The migrated or invaded cells were then visualized and counted from 6 randomly selected fields (x200 magnification).

Cell cycle analysis. Cell cycle phase analysis was performed by PI staining. MDA-MB-231 cells were treated with different concentrations of evodiamine for $24 \mathrm{~h}$. The cells were harvested, washed with PBS, and fixed in ice-cold $70 \%$ ethanol at $4^{\circ} \mathrm{C}$ overnight. The cells were washed with ice-cold PBS and stained with PI $(50 \mu \mathrm{g} / \mathrm{ml})$ in the dark for $30 \mathrm{~min}$. Cell cycle distribution was analyzed using Mcycle software (Beckman Coulter, Fullerton, CA, USA).

Annexin V-FITC binding assay. The quantification of apoptotic cells was performed by flow cytometric analysis using an Annexin V-FITC/PI Apoptosis kit (Beckman Coulter, Miami, FL, USA). MDA-MB-231 cells were treated with different concentrations of evodiamine for $48 \mathrm{~h}$. Annexin V and PI staining was performed according to the manufacturer's instructions. After staining, the quantification of apoptotic cells was measured with a flow cytometer (Beckman Coulter). The percentage of early apoptosis was detected by Annexin V-positivity and PI-negativity, while the percentage of advanced apoptosis was detected by Annexin V-positivity and PI-positivity.

Acridine orange (AO) fluorescence staining. Apoptotic morphological analysis was performed using AO fluorescence staining. MDA-MB-231 cells were seeded on coverslips in 6 -well plates and treated with evodiamine for $48 \mathrm{~h}$. The coverslips were fixed with $95 \%$ ethanol for $15 \mathrm{~min}$, acidified with $1 \%$ acetic acid for $30 \mathrm{sec}$, dyed with $\mathrm{AO}(0.1 \mathrm{mg} / \mathrm{ml})$ for $10 \mathrm{~min}$, differentiated with $\mathrm{CaCl}_{2}(0.1 \mathrm{~mol} / \mathrm{l})$ for $2 \mathrm{~min}$, and observed under a fluorescence microscope (x400 magnification). 
Terminal deoxynucleotidyl transferase-mediated dUTP nick end labeling (TUNEL) assay. Apoptotic cells in sections of tumor tissues were detected using a KeyGene TUNEL apoptosis detection kit (Kai-ji, Nanjing, China) according to the manufacturer's protocol. Briefly, tumor histological sections were permeabilized with $20 \mu \mathrm{g} / \mathrm{ml}$ protease $\mathrm{K}$. Apoptosis was detected by labeling the 3'-OH ends of the fragmented DNA with Biotin-11-dUTP under TdT enzyme at $37^{\circ} \mathrm{C}$ for $60 \mathrm{~min}$. The tumor slides were then incubated with streptavidin horseradish peroxidase (streptavidin-HRP) conjugate at $37^{\circ} \mathrm{C}$ for $30 \mathrm{~min}$, followed by incubation with DAB and after-stain with hematoxylin. The TUNEL-positive cells (dark brown nuclei) were counted in 6 randomly selected fields under a microscope (x200 magnification). The apoptotic index (AI) was calculated as follows: $\mathrm{AI}(\%)=$ number of apoptotic cells/total number of cells $\mathrm{x} 100 \%$.

In-cell western analysis. In-cell western assay (19) was used to determine the level of protein expression in cells. MDA-MB-231 cells $\left(1.5 \times 10^{5} / \mathrm{ml}\right)$ were plated in 96 -well plates. The next day, the cells were treated with $60 \mu \mathrm{M}$ evodiamine for 24 or $48 \mathrm{~h}$. The cells were fixed with $4 \%$ formaldehyde for $20 \mathrm{~min}$ and washed with $0.1 \%$ Triton, and finally blocked with $10 \%$ non-fat milk overnight at $4^{\circ} \mathrm{C}$. The cells were then incubated with the primary antibodies: Bcl-2, Bax, cyclin D1, p27 ${ }^{\text {Kipl }}$, CDK6, MMP-2, MMP-9, uPA, uPAR, p38 MAPK, p-p38 MAPK, ERK, p-ERK, SAPK/JNK and p-SAPK/JNK overnight at $4^{\circ} \mathrm{C}$, respectively. The housekeeping protein, GAPDH, was added to each well at the same time as the control. The wells were then incubated with the corresponding secondary IRDye ${ }^{\mathrm{TM}} 680 \mathrm{DX}$ (red fluorescence) or IRDye $^{\mathrm{TM}} 800 \mathrm{DX}$ (green fluorescence) fluorescence antibody recommended by the manufacturer (Rockland, Gilbertsville, PA, USA) in the dark. Images were obtained using the Odyssey Infrared Imaging System (LI-COR Biosciences). The levels of protein expression were calculated as the ratio of the intensity of the target protein to that of GAPDH. The experiments were carried out in triplicate.

Animal tumor xenograft model and treatment with drugs. Six-week-old female BALB/c athymic mice were obtained from the Laboratory Animal Center at Shanghai University of Traditional Chinese Medicine. The mice were housed in barrier facilities with rodent chow and water under a specified-pathogen-free (SPF) condition throughout the experimental duration. MDA-MB-231 cancer cells $\left(3 \times 10^{6}\right.$, suspended in $100 \mu 1$ of serum-free DMEM) were injected into the mammary fat pad of the mice. One day after tumor cell transplantation, $10 \mathrm{mg} / \mathrm{kg}$ evodiamine (17) was intraperitoneally (i.p.) injected once every 2 days. The body weight of each mouse was measured each week after treatment. All mice were sacrificed after drug administration for 2 months, and the tumors were removed and weighed. The lung and tumor tissues were fixed with formalin. Thin sections were stained with hematoxylin and eosin (H\&E) and metastatic nodules present in the lungs were counted. Representative fields (x100 magnification) for each group were photographed. All procedures conformed to the consideration of animal welfare and were approved by the Ethics Committee of Shanghai University of Traditional Chinese Medicine.

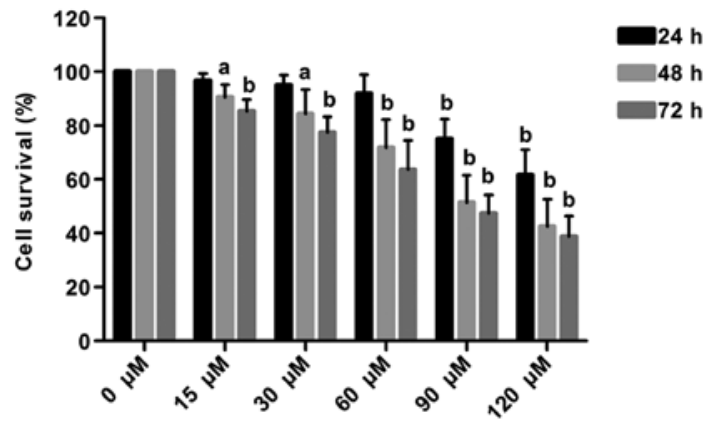

Figure 1. Effect of evodiamine on MDA-MB-231 cell viability. The effect of evodiamine on MDA-MB-231 cell viability was observed by MTT assay. Cells were treated with evodiamine at $0,15,30,60,90$ and $120 \mu \mathrm{M}$ for 24 , 48 and $72 \mathrm{~h}$, respectively. Values are represented as the means $\pm \operatorname{SD}(n=3)$. ${ }^{\mathrm{a}} \mathrm{P}<0.05,{ }^{\mathrm{b}} \mathrm{P}<0.01$, vs. untreated cells.

Statistical analysis. Experimental results are presented as the means \pm standard deviation (SD). Differences were evaluated by the Student's t-test or one-way analysis of variance (ANOVA). $\mathrm{P}<0.05$ was considered to indicate a statistically significant result.

\section{Results}

Anti-proliferative effects of evodiamine in MDA-MB-231 cells. The growth of MDA-MB-231 cells was inhibited by evodiamine in a dose- and time-dependent manner. Treatment at doses of 15,30 and $60 \mu \mathrm{M}$ did not cause cytotoxicity in MDA-MB-231 cells at $24 \mathrm{~h}(\mathrm{P}>0.05)$; however, the survival rates of MDA-MB-231 cells were significantly decreased to 75.06 and $61.76 \%$ following treatment with 90 and $120 \mu \mathrm{M}$, respectively $(\mathrm{P}<0.01)$. Following treatment at doses of 15,30 , 60,90 and $120 \mu \mathrm{M}$ for $48 \mathrm{~h}$, the survival rates were decreased to $90.50,84.40,71.70,51.44$ and $42.47 \%$, respectively $(\mathrm{P}<0.01)$. The half maximal inhibitory concentration $\left(\mathrm{IC}_{50}\right)$ at $48 \mathrm{~h}$ was $\sim 90 \mu \mathrm{M}$. Following treatment at doses of 15, 30, 60, 90 and $120 \mu \mathrm{M}$ for $72 \mathrm{~h}$, the survival rates were decreased to 85.44 , $77.45,63.69,47.49$ and $38.77 \%$, respectively $(\mathrm{P}<0.01)$ (Fig. 1).

Evodiamine inhibits the migration and invasion ability of $M D A-M B-231$ cells. In the wound healing assay, the gaps in the cells treated with 15,30 and $60 \mu \mathrm{M}$ evodiamine were wider than that in the untreated group (Fig. 2A). In the Transwell migration assay, the cells that had migrated to the lower chambers was reduced by evodiamine in a concentration-dependent manner. The number of migrated cells following treatment with 15, 30 and $60 \mu \mathrm{M}$ evodiamine were reduced to $\sim 90.41$, 47.93 and $34.72 \%$, respectively $(\mathrm{P}<0.01)$ (Fig. $2 \mathrm{~B}$ and $\mathrm{D})$. In the Transwell invasion assay, the number of cells invaded through the Matrigel-coated filter was reduced by evodiamine dosedependently. Compared with the untreated cells, the number of invaded cells following treatment 15,30 and $60 \mu \mathrm{M}$ evodiamine was reduced to $\sim 77.31,50.14$ and $33.89 \%$, respectively $(\mathrm{P}<0.05$ or $\mathrm{P}<0.01)$ (Fig. $2 \mathrm{C}$ and $\mathrm{D})$.

Evodiamine induces G0/G1 cell cycle arrest of MDA-MB-231 cells. Exposure to different concentrations of evodiamine $(0,15$, $30,60,90$ and $120 \mu \mathrm{M}$ ) caused G0/G1 arrest of MDA-MB-231 
A
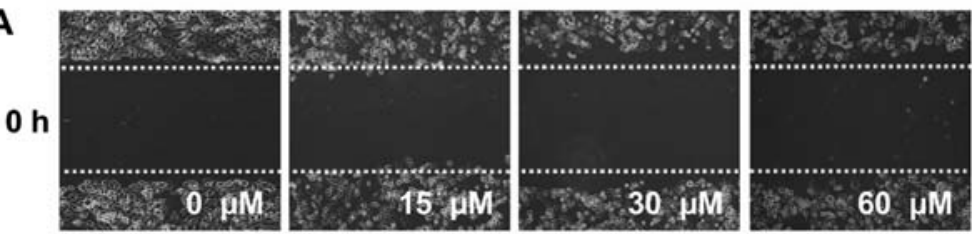

$24 \mathrm{~h}$
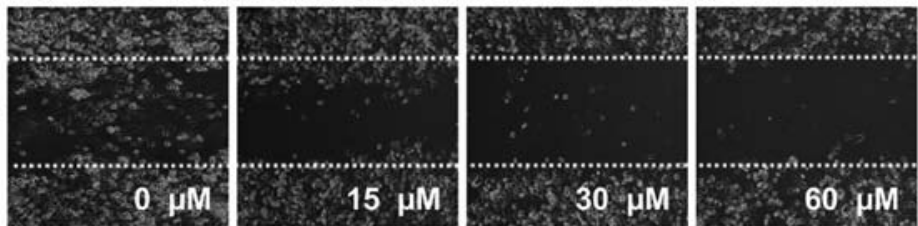

B
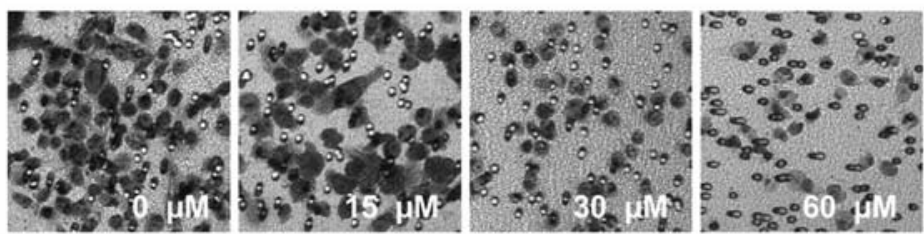

C
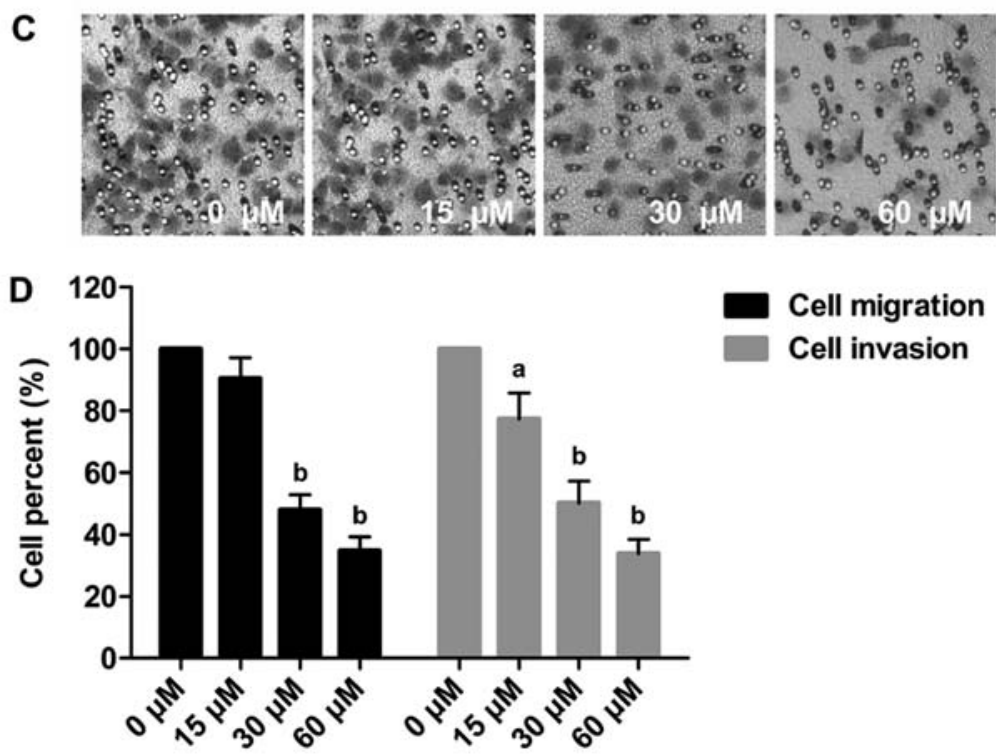

Cell migration

Cell invasion

Figure 2. Effect of evodiamine on MDA-MB-231 cell migration and invasion. (A) Images of the wound healing assays. The wounded monolayer was incubated in FBS-free DMEM containing $0,15,30$ or $60 \mu \mathrm{M}$ of evodiamine for $24 \mathrm{~h}$. (B) Transwell chamber migration assay. (C) Transwell chamber invasion assay. MDA-MB-231 cells were treated with $0,15,30$ or $60 \mu \mathrm{M}$ evodiamine for $24 \mathrm{~h}$. (D) Percent of cell migration and cell invasion. Values are represented as means $\pm \mathrm{SD}(\mathrm{n}=3)$. ${ }^{\mathrm{a}} \mathrm{P}<0.05,{ }^{\mathrm{b}} \mathrm{P}<0.01$, vs. untreated cells.

cells and a dose-dependent accumulation in the sub-G1 phase. Concomitant with this result, there was a dose-dependent decrease in the $\mathrm{S}$ and $\mathrm{G} 2 / \mathrm{M}$ phases, when compared with the untreated cells (Fig. 3 and Table I).

Evodiamine induces apoptosis in MDA-MB-231 cells. To confirm whether evodiamine inhibits MDA-MB-231 cell viability due to apoptosis, morphological observation and Annexin V-FITC binding assay of MDA-MB-231 cells were conducted. Chromatin condensation, nuclear fragmentation and apoptotic bodies were found in the evodiamine-treated cells (Fig. 4A). This result indicated that MDA-MB-231 cells underwent the typical morphological changes of apoptosis when exposed to $60 \mu \mathrm{M}$ evodiamine for $48 \mathrm{~h}$. To quantify apoptosis, the Annexin V-FITC apoptosis assay was further carried out by FACS. Treatment of MDA-MB-231 cells with different concentrations of evodiamine resulted in a dosedependent increase in apoptotic cells (Fig. 4B). The detailed percentages of early apoptosis, late apoptosis and total apoptosis in MDA-MB-231 cells were calculated (Table II).

Evodiamine regulates the expression of proteins related to apoptosis, cell cycle, cell migration and invasion in the $M D A-M B-231$ cells. To investigate the underlying mechanism of the induction of apoptosis and cell cycle arrest and inhibition of cell migration and invasion by evodiamine, expression of proteins related to apoptosis, cell cycle and cell migration and invasion was determined by in-cell western analysis. Compared to untreated cells, evodiamine significantly decreased the level of Bcl-2 $(\mathrm{P}<0.01)$ and increased the level of $\mathrm{Bax}(\mathrm{P}<0.05)$, resulting in upregulation of the Bax/ Bcl-2 ratio. Evodiamine treatment decreased the levels of cyclin D1 $(\mathrm{P}<0.05)$ and CDK6 $(\mathrm{P}<0.01)$ and increased the level of $\mathrm{p} 27^{\mathrm{Kip} 1}(\mathrm{P}<0.01)$; as well as decreased the levels of MMP-9, uPA and UPAR $(\mathrm{P}<0.05)$, whereas evodiamine treatment did not affect MMP-2 expression (P>0.05) (Fig. 5). 
Table I. Cell cycle distribution in MDA-MB-231 cells exposed to different concentrations of evodiamine for $24 \mathrm{~h}$.

\begin{tabular}{cccrr}
\hline Evodiamine $(\mu \mathrm{M})$ & Sub-G1 $(\%)$ & G0/G1 $(\%)$ & S $(\%)$ & G2/M $(\%)$ \\
\hline 0 & $0.13 \pm 0.03$ & $53.29 \pm 2.73$ & $15.50 \pm 0.96$ & $27.01 \pm 0.56$ \\
15 & $7.79 \pm 1.88^{\mathrm{b}}$ & $74.92 \pm 2.35^{\mathrm{b}}$ & $6.48 \pm 1.30$ & $8.04 \pm 2.75$ \\
30 & $10.69 \pm 3.89^{\mathrm{b}}$ & $74.20 \pm 2.02^{\mathrm{b}}$ & $5.27 \pm 2.29$ & $6.13 \pm 3.46$ \\
60 & $15.93 \pm 1.89^{\mathrm{b}}$ & $72.94 \pm 0.29^{\mathrm{b}}$ & $3.38 \pm 0.68$ & $3.85 \pm 1.46$ \\
90 & $24.28 \pm 3.46^{\mathrm{b}}$ & $65.30 \pm 2.69^{\mathrm{b}}$ & $3.99 \pm 1.47$ & $2.46 \pm 1.17$ \\
120 & $32.19 \pm 1.84^{\mathrm{b}}$ & $60.12 \pm 1.26^{\mathrm{a}}$ & $3.71 \pm 0.13$ & \\
\hline
\end{tabular}

Values are represented as the means $\pm \mathrm{SD}$. ${ }^{\mathrm{a}} \mathrm{P}<0.05,{ }^{\mathrm{b}} \mathrm{P}<0.01$, vs. untreated cells.

Table II. Percentage of apoptosis in the MDA-MB-231 cells exposed to different concentrations of evodiamine for $48 \mathrm{~h}$.

\begin{tabular}{|c|c|c|c|}
\hline \multirow[b]{2}{*}{ Evodiamine $(\mu \mathrm{M})$} & \multirow{2}{*}{$\frac{\text { Early apoptosis }(\%)}{\text { Annexin } \mathrm{V}^{+}, \mathrm{PI}^{-}}$} & \multirow{2}{*}{$\frac{\text { Late apoptosis }(\%)}{\text { Annexin } \mathrm{V}^{+}, \mathrm{PI}^{+}}$} & \multirow[t]{2}{*}{ Total apoptosis $(\%)$} \\
\hline & & & \\
\hline 0 & $1.24 \pm 0.52$ & $0.00 \pm 0.01$ & $1.24 \pm 0.52$ \\
\hline 15 & $11.89 \pm 0.73$ & $0.04 \pm 0.01$ & $11.93 \pm 0.74^{\mathrm{b}}$ \\
\hline 30 & $18.98 \pm 6.06$ & $0.02 \pm 0.01$ & $19.00 \pm 6.05^{\mathrm{b}}$ \\
\hline 60 & $31.44 \pm 1.78$ & $0.05 \pm 0.06$ & $31.48 \pm 1.83^{\mathrm{b}}$ \\
\hline 90 & $50.55 \pm 1.98$ & $0.08 \pm 0.06$ & $50.63 \pm 1.96^{\mathrm{b}}$ \\
\hline 120 & $57.98 \pm 2.60$ & $0.17 \pm 0.07$ & $58.15 \pm 2.55^{\mathrm{b}}$ \\
\hline
\end{tabular}

Values are represented as the means $\pm \mathrm{SD}$. ${ }^{\mathrm{b}} \mathrm{P}<0.01$ vs. untreated cells.

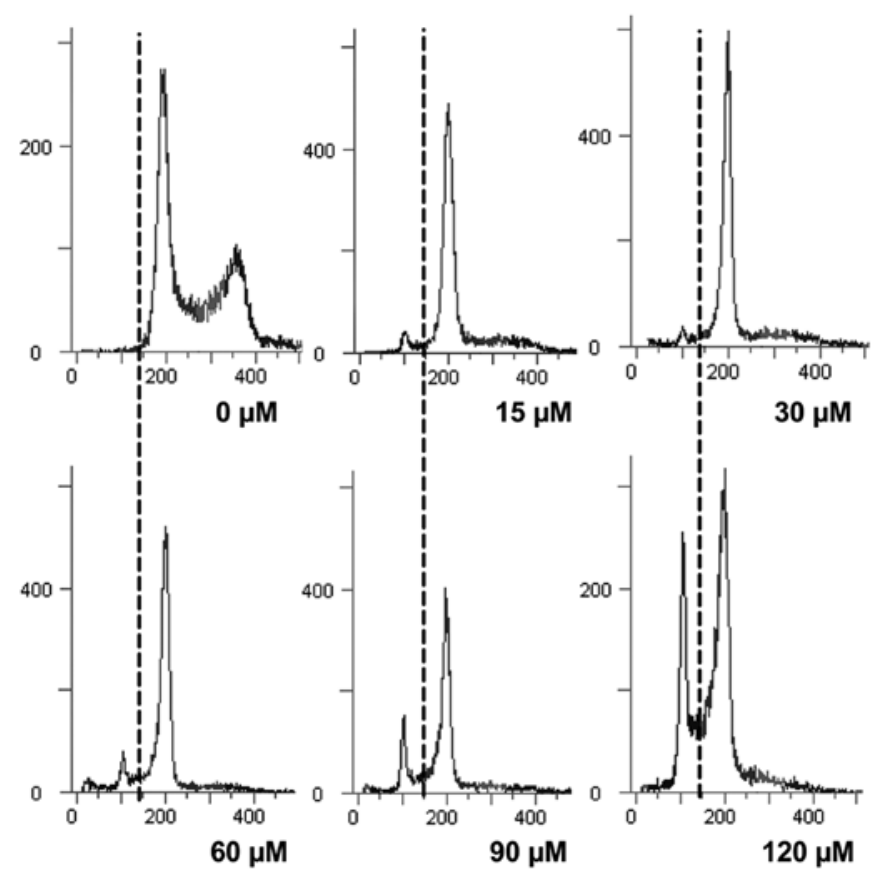

Figure 3. Effect of evodiamine on the cell cycle distribution of MDA-MB-231 cells. Cells were cultured in $0,15,30,60,90$ and $120 \mu \mathrm{M}$ of evodiamine for $24 \mathrm{~h}$. Representative flow cytometry profiles are shown. Distribution of the cell cycle in MDA-MB-231 cells at different phases. The peak located left of the dashed line represents the sub-G1 apoptotic peak.
Evodiamine regulates the levels of $p$-ERK and p-p38 MAPK in $M D A-M B-231$ cells. The expression levels of p-ERK, p-p38 MAPK, p-JNK and each non-phosphorylated form were detected by in-cell western analysis. The levels of p-ERK, p-p38 MAPK and p-JNK expression were normalized to nonphosphorylated ERK, p38 MAPK and JNK, respectively. As shown in Fig. 6A, compared to the untreated cells, the levels of p-ERK and p-p38 MAPK were significantly decreased following exposure to evodiamine for $24 \mathrm{~h}(\mathrm{P}<0.05)$. Moreover, compared to the untreated cells, the level of $\mathrm{p}-\mathrm{ERK}$ was significantly decreased $(\mathrm{P}<0.05)$, while the level of $\mathrm{p}-\mathrm{p} 38$ MAPK was increased following exposure to evodiamine for $48 \mathrm{~h}(\mathrm{P}<0.05)$. The level of $\mathrm{p}-\mathrm{JNK}$ remained constant following evodiamine treatment for 24 or $48 \mathrm{~h}(\mathrm{P}>0.05)$. These results indicate that evodiamine regulates the activities of the ERK and p38 MAPK pathways.

The role of ERK and p38 MAPK in the induction of apoptosis and inhibition of migration. To address the role of ERK and p38 MAPK in evodiamine-induced apoptosis, MDA-MB-231 cells were treated with $20 \mu \mathrm{M}$ PD98059 (ERK inhibitor), or $30 \mu \mathrm{M}$ SB203580 (p38 MAPK inhibitor) alone and co-treated with $60 \mu \mathrm{M}$ evodiamine for $48 \mathrm{~h}$. Co-treatment of $20 \mu \mathrm{M}$ PD98059 or $30 \mu \mathrm{M}$ SB203580 with $60 \mu \mathrm{M}$ evodiamine reduced the cell viability to 37.52 or $38.50 \%$, respectively. Cell survival rate was decreased $\sim 10 \%$, compared to that following treatment with $60 \mu \mathrm{M}$ evodiamine alone $(\mathrm{P}<0.05)$. FACS revealed that the percentage of apoptotic cells was significantly higher 

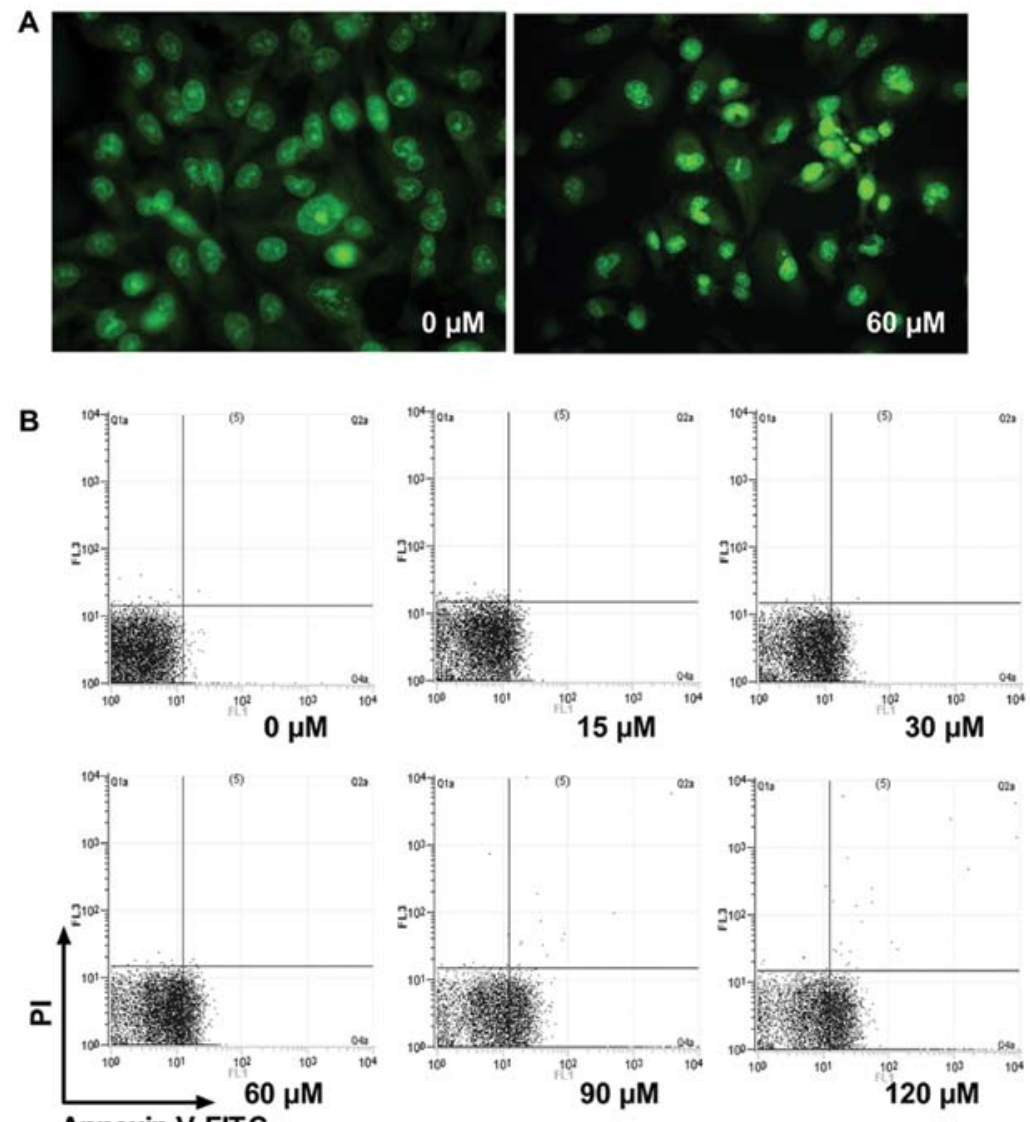

Figure 4. Evodiamine induces apoptosis in MDA-MB-231 cells. (A) MDA-MB-231 cells were treated with 0 and $60 \mu \mathrm{M}$ evodiamine for $48 \mathrm{~h}$, respectively, stained with acridine orange (AO), and photographed using fluorescence microscope. (B) MDA-MB-231 cells were treated with 0, 15, 30, 60, 90 and 120 $\mu \mathrm{M}$ evodiamine for $48 \mathrm{~h}$ and analyzed by FACS. Representative flow cytometry profiles are shown. The bottom-right quadrant indicates early apoptosis, the topright quadrant indicates late apoptosis.

A

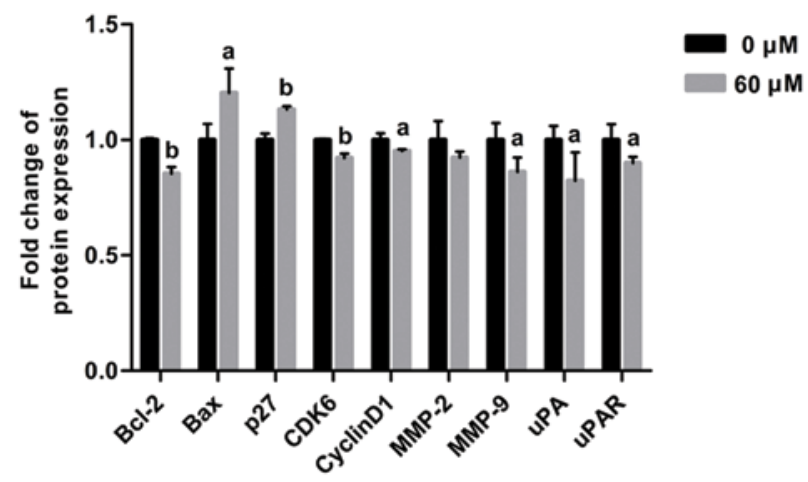

B 680 channel 800 channel 6808800 channel

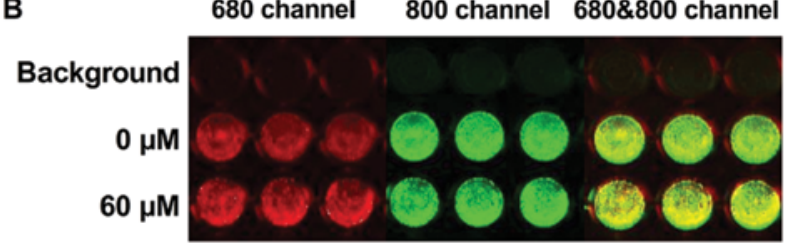

Figure 5. Effect of evodiamine on the expression of Bcl-2, Bax, p27 ${ }^{\text {Kipl } 1}$, cyclin-dependent kinase 6 (CDK6), cyclin D1, MMP-2, MMP-9, urokinase-type plasminogen activator (uPA) and uPAR in MDA-MB-231 cells. The expression of p27 ${ }^{\text {Kipl }}$, CDK6, cyclin D1, MMP-2, MMP-9, uPA and uPAR was determined after treatment with $60 \mu \mathrm{M}$ evodiamine for $24 \mathrm{~h}$. The expression of Bcl-2 and Bax was determined after treatment with $60 \mu \mathrm{M}$ evodiamine for $48 \mathrm{~h}$. (A) The fluorescence intensity ratio of proteins to GAPDH is shown as relative expression. Values are represented as the means $\pm \mathrm{SD}$. ${ }^{\mathrm{a}} \mathrm{P}<0.05$, ${ }^{\mathrm{b}} \mathrm{P}<0.01$, vs. untreated cells. (B) A representative image is shown. Red fluorescence indicates the expression of GAPDH in 680 channel and green fluorescence indicates the expression of MMP-9 in 800 channel. Experiments were repeated with similar results. 

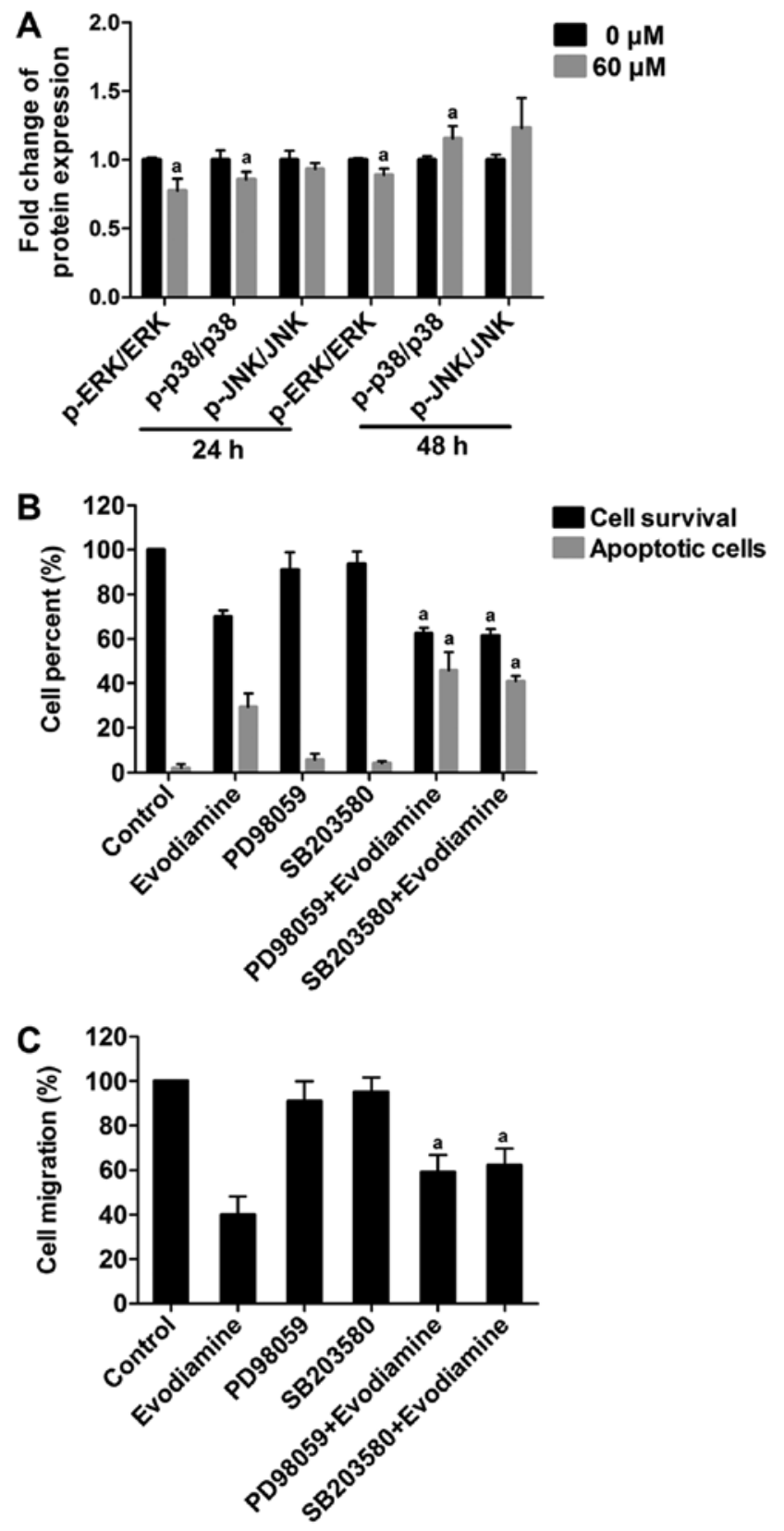

Figure 6. Effect of extracellular signal-regulated kinase (ERK) and p38 mitogen-activated protein kinase (p38 MAPK) on evodiamine-induced apoptosis and inhibition of migration in MDA-MB-231 cells. (A) The levels of p-ERK, p-p38 MAPK and p-JNK were assessed by in-cell western analysis after treatment with $60 \mu \mathrm{M}$ evodiamine for 24 and $48 \mathrm{~h}$, respectively. ${ }^{\mathrm{a}} \mathrm{P}<0.05$, vs. untreated cells. (B) Effect of ERK and p38 MAPK on evodiamineinduced cell growth inhibition and apoptosis. Cell viability was measured by MTT assay after treatment with $20 \mu \mathrm{M}$ PD98059 and $30 \mu \mathrm{M}$ SB203580 with or without $60 \mu \mathrm{M}$ evodiamine for $48 \mathrm{~h}$. Total percentage of apoptotic cells was calculated by FACS after treatment with $20 \mu \mathrm{M}$ PD98059 and $30 \mu \mathrm{M}$ SB203580 with or without $60 \mu \mathrm{M}$ evodiamine for $48 \mathrm{~h}$. (C) Effect of ERK and $\mathrm{p} 38$ MAPK on evodiamine-inhibited cell migration. Cell migration was measured by Transwell migration assay. Treatment with $20 \mu \mathrm{M}$ PD98059 and $10 \mu \mathrm{M}$ SB203580 with or without $60 \mu \mathrm{M}$ evodiamine for $24 \mathrm{~h}$. Values are represented as the means $\pm \mathrm{SD}$. ${ }^{\mathrm{a}} \mathrm{P}<0.05,{ }^{\mathrm{b}} \mathrm{P}<0.01$ vs. $60 \mu \mathrm{M}$ treatment of evodiamine alone.

following treatment with the two inhibitors in combination with $60 \mu \mathrm{M}$ evodiamine, compared to the cultures exposed to $60 \mu \mathrm{M}$ evodiamine alone $(\mathrm{P}<0.05)$ (Fig. 6B).
Furthermore, to address the role of ERK and p38 MAPK in evodiamine-inhibited migration, MDA-MB-231 cells were treated with $20 \mu \mathrm{M}$ PD98059 or $10 \mu \mathrm{M}$ SB203580 alone or co-treated with $60 \mu \mathrm{M}$ evodiamine for $24 \mathrm{~h}$. As shown in Fig. 6C, co-treatment of $20 \mu \mathrm{M}$ PD98059 or $10 \mu \mathrm{M}$ SB203580 with $60 \mu \mathrm{M}$ evodiamine increased the cell migration rate $20 \%$, compared to that following treatment with $60 \mu \mathrm{M}$ evodiamine alone $(\mathrm{P}<0.05)$ (Fig. 6C). These results suggest that the ERK and p38 MAPK pathways may play an important role in evodiamine-induced apoptosis and inhibition of migration in MDA-MB-231 cells.

Evodiamine administration retards tumor growth, induces apoptosis and inhibits the pulmonary metastasis of $M D A-M B-231$ cells in nude mice. The average body weights of the control (saline-treated) and evodiamine-treated mice did not differ significantly throughout the study (Fig. 7A). Movement, digestion and swelling seemed normal in the evodiamine-treated mice. Moreover, the tumor weight in the evodiamine-treated group was lower than that of the control group $(\mathrm{P}<0.01)$ (Fig. 7B). H\&E staining revealed a relatively higher nuclear to cytoplasmic ratio in the tumors from the control group when compared with the ratio in the evodiaminetreated group. TUNEL staining demonstrated that the number of apoptotic-positive cells in the evodiamine-treated group was significantly higher than that in the control group (Fig. 7C). The AI was subsequently calculated. The average AI was $13 \%$ in the evodiamine-treated group (Fig. 7D). Furthermore, the lungs in the evodiamine-treated mice contained less metastasized MDA-MB-231 cells morphologically, when compared to the control group (Fig. 7C). The average number of tumor nodules in the control group was 22 , while that in the evodiamine-treated group was 13 , indicating evodiamine treatment significantly decreased lung metastasis $(\mathrm{P}<0.01)$ (Fig. 7E). Collectively, these results suggest that evodiamine administration significantly retards tumor growth, induces apoptosis and inhibits pulmonary metastasis, without an abnormal response in the MDA-MB-231 xenograft model.

\section{Discussion}

Evodiamine was found to possess antitumor potential in different cancer cell lines, however, there is no available information on the effects of evodiamine on highly metastasis human breast cancer MDA-MB-231 cells. Moreover, the mechanism involved in the inhibition of growth and metastasis of MDA-MB-231 cells by evodiamine requires further investigation. In the present study, for the first time, we investigated the effects of evodiamine on the growth, migration and invasion of MDA-MB-231 cells and primarily focused on its molecular mechanism.

We found that evodiamine inhibited cell motility, migration and invasion of MDA-MB-231 cells (Fig. 2) and exerts an antimetastasis effect by inhibiting pulmonary metastatic nodules in xenograft BALB/c nude mice (Fig. 7). During the progression of cancer cell metastasis, matrix metalloproteinases (MMPs) play a crucial role in tumor invasion and metastasis formation due to their ability to degrade extracellular matrix proteins (20). In our study, the level of MMP-9 was downregulated by evodiamine (Fig. 5), and this result 

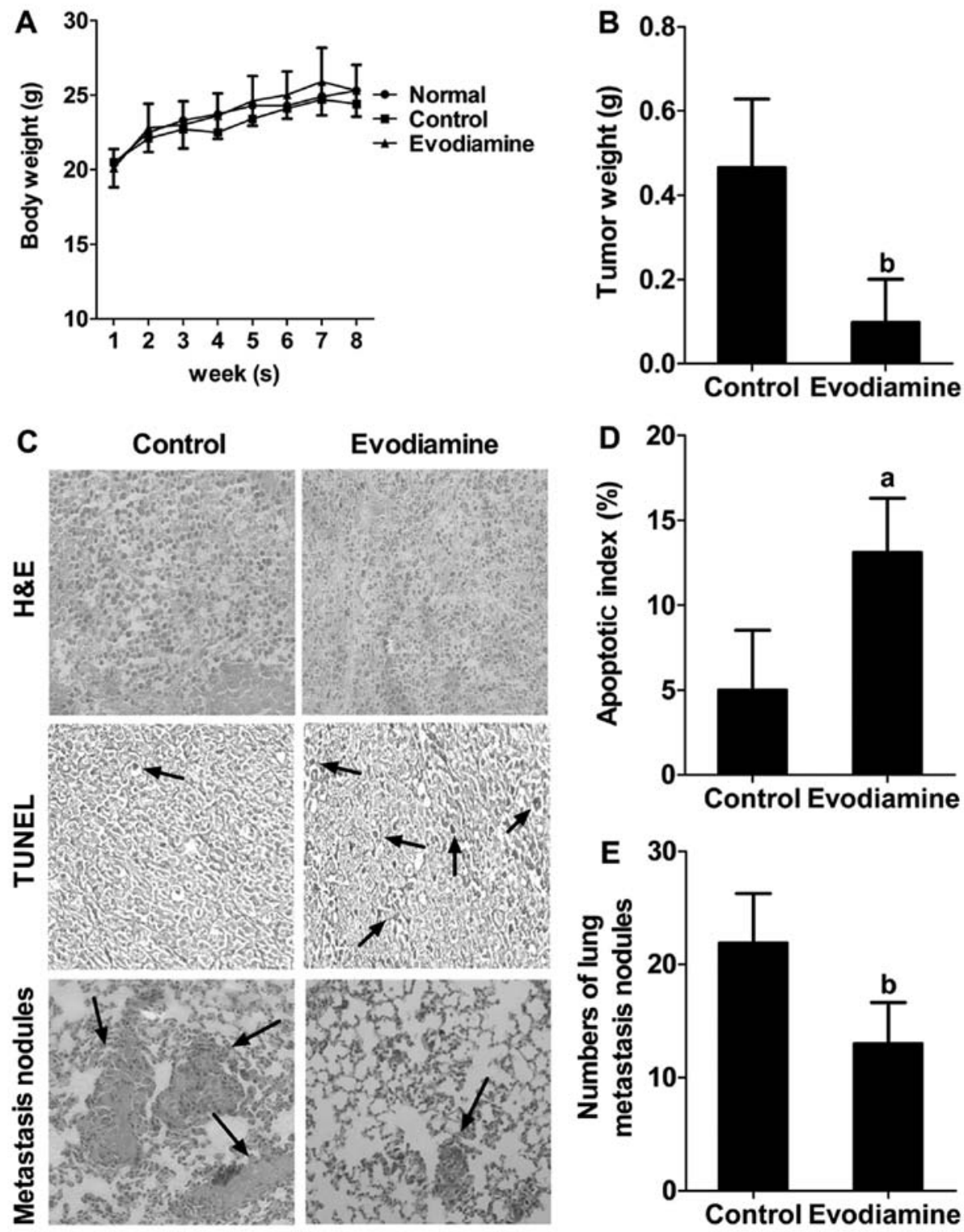

Figure 7. Effect of evodiamine administration on tumor growth, apoptosis and pulmonary metastasis in the MDA-MB-231 xenograft model. (A) Average mouse body weights. (B) Average tumor weights. (C) Histological observation of tumor cells by hematoxylin and eosin (H\&E) staining (upper), TUNEL staining (middle) and lung nodules (lower). (D) Apoptotic index (AI). At least 6 randomly selected fields on each tumor section were scored for calculation of TUNEL-positive cells. (E) Quantification of lung metastatic nodules. Values are represented as the means \pm SD (control group, $n=8$; evodiamine-treated group, $\mathrm{n}=8) .{ }^{\mathrm{a}} \mathrm{P}<0.05,{ }^{\mathrm{b}} \mathrm{P}<0.01$, vs. control group.

was consistent with the evidence of evodiamine blocking the expression of TNF-induced NF- $\kappa \mathrm{B}$-regulated gene products including MMP-9 in KBM-5 cells (18). uPA and its receptor uPAR are usually overexpressed in breast cancer cells. uPA binding to uPAR directly contributes to the degradation of the extracellular matrix, and also mediates activation of MMPs, thereby promoting cancer cell invasion and migration $(21,22)$. The levels of uPA and uPAR were downregulated by evodiamine (Fig. 5). Therefore, inhibition of the levels of MMP-9, UPA and UPAR may be, at least in part, responsible for the antimetastatic potential of evodiamine against MDA-MB-231 cells.

Treatment of MDA-MB-231 cells with evodiamine resulted in significant G0/G1 phase arrest (Fig. 3) and apoptosis induction (Figs. 4 and 7). Control of cell cycle progression in cancer cells is regarded to be an effective strategy for inhibition of tumor cell proliferation. Cyclin Dl and cyclin-dependent kinase 6 (CDK6) are overexpressed in breast cancer and play a role in $\mathrm{Gl}$ progression and oncogenesis. One of the CDK inhibitors, $\mathrm{p} 27^{\mathrm{Kip} 1}$, inhibits a wide variety of cyclinCDK complexes in vitro, and its overexpression blocks the progression of cells through the Gl phase $(23,24)$. In our study, evodiamine treatment caused G0/G1 phase arrest accompanied by downregulation of the expression of cyclin D1 and CDK6 and upregulation of the expression of $\mathrm{p} 27^{\mathrm{Kipl}}$ (Fig. 5). Previous studies have reported that evodiamine blocks G0/G1 phase in L929 cells (25), induces S phase arrest in LoVo cells (11) and causes blockage of the G2/M phase in LNCaP cells (12). These studies showed that evodiamine arrests the cancer cell cycle at different phases. This may provide explanations 
concerning the types of cell lines and their specific response to evodiamine.

In our study, we found that evodiamine plays an antiproliferative role via inducing MDA-MB-231 cell apoptosis. Apoptosis is tightly regulated by anti-apoptotic and proapoptotic molecules, including proteins of the Bcl-2 family. Among them, Bcl-2 and its dominant inhibitor Bax are key regulators of several survival and apoptosis pathways. Overexpression of Bcl-2 enhances cell survival by suppressing apoptosis, but overexpression of Bax accelerates cell death, and the ratio of $\mathrm{Bax} / \mathrm{Bcl}-2$ plays a critical role in determining whether cells will undergo apoptosis (26). Here, evodiamine increased pro-apoptotic Bax expression and decreased antiapoptotic Bcl-2 expression, leading to upregulation of the ratio of $\mathrm{Bax} / \mathrm{Bcl}-2$ (Fig. 5). Thus, this finding confirmed that MDA-MB-231 cells underwent apoptosis induced by evodiamine through the Bax/Bal-2 pathway.

Recent studies have demonstrated that mitogen-activated protein kinases (MAPKs), including Jun N-terminus kinase (JNK), p38 mitogen-activated protein kinase (p38 MAPK) and extracellular signal-regulated kinase (ERK), play crucial roles in cell survival, apoptosis and migration in tumor development and progression (27-29). The aberrant activation of ERK and p38 MAPK is associated with the promotion of migration. Activated ERK1/2 was found to result in high uPA expression, rapid cell proliferation and the migration of breast cancer cells $(30,31)$. Daintain/AIF-1 activated p38 MAPK signaling pathway contributed to the upregulation of TNF- $\alpha$ and led to enhanced migration of MDA-MB-231 and MCF-7 cells (32). In our study, the expression levels of p-ERK and p-p38 MAPK were both downregulated following exposure to evodiamine for $24 \mathrm{~h}$ in MDA-MB-231 cells (Fig. 6A). These findings may account for the inhibition of MDA-MB-231 cell migration and invasion by evodiamine, and such anti-metastatic activities of evodiamine may partly involve the suppression of ERK and p38 MAPK signaling pathways.

In general, the activation of JNK/SAPK and p38 MAPK is associated with promotion of apoptosis, while ERK activity inhibits apoptosis (33). In the present study, the expression of p-ERK was downregulated while the expression of p-p38 MAPK was upregulated following exposure to evodiamine for $48 \mathrm{~h}$ in MDA-MB-231 cells (Fig. 6A). This result was consistent with the inhibitory effect of evodiamine on proliferation of A375-S2 cells. Evodiamine blocked the protective role of ERK in A375-S2 cells through the downregulation of p-ERK expression (34). Thus, evodiamine induces cell apoptosis through ERK inactivation and p38 MAPK activation.

According to the above findings, indicating that evodiamine regulates p-ERK and p-p38 MAPK, it was hypothesized that ERK and p38 MAPK may have some effects on evodiaminemediated cell metastasis and apoptosis. In the present study, the anti-metastastic effect of evodiamine was partly blocked by PD98059 and SB203580 (Fig. 6C). Therefore, we may conclude that evodiamine-inhibited migration of MDA-MB231 cells may partly occur through suppression of the ERK or p38 MAPK pathway. When ERK or p38 MAPK was blocked, the anti-migration potential of evodiamine was reduced.

Zelivianski et al (35) found that the ERK inhibitor PD98059 enhanced docetaxel-induced apoptosis of androgenindependent human prostate cancer cells. In the present study,
PD98059 or SB203580 enhanced the potential of evodiamineinduced growth suppression in breast cancer MDA-MB-231 cells (Fig. 6B). The mechanism of PD98059 involved in evodiamine-mediated cell apoptosis was previously associated with decreased expression of c-Myc and cyclin D1 which are key targets of the MAPK pathway and activate the caspase cascade (36). Although activation of p38, to some extent, accounted for the growth inhibition by evodiamine, p38 inhibition also synergized evodiamine-induced cell apoptosis. p38 had dual effects during the regulation of cell growth. It phosphorylated p53, was involved in Fas/FasL-mediated apoptosis pathway and induced Bax translocation to induce apoptosis, otherwise, it initiated the cell survival pathway, and inhibited apoptosis signal generation $(37,38)$. In addition, many of the signals from other pathways may converge with that of the MAPK cascade and downstream factors may be involved in this response. For these reasons, the detailed mechanisms involved in the synergistic induction of apoptosis generating by co-treatment of PD98059 and SB203580 with evodiamine require further investigation.

In conclusion, the results of the present study indicate that evodiamine not only inhibits proliferation, induces G0/G1 phase arrest and apoptosis, but also inhibits migration and invasion of human breast cancer MDA-MB-231 cells. Moreover, evodiamine regulated ERK and p38 MAPK activities, and its pro-apoptotic and anti-metastastic effects were enhanced or weakened by an ERK inhibitor and a p38 MAPK inhibitor, respectively. Although further investigations are needed to verify the anticancer mechanism of evodiamine, this study emphasizes the promising application of evodiamine in breast cancer treatment.

\section{Acknowledgements}

The present study was supported by the Leading Academic Discipline Project of Shanghai Municipal Education Commission (no. J50301) and E-institutes of Shanghai Municipal Education Commission (no. E03008).

\section{References}

1. Jemal A, Bray F, Center MM, Ferlay J, Ward E and Forman D: Global cancer statistics. CA Cancer J Clin 61: 69-90, 2011.

2. Weinberg RA: How cancer arises. Sci Am 275: 62-70, 1996.

3 . Weigelt B, Peterse JL and van't Veer LJ: Breast cancer metastasis: markers and models. Nat Rev Cancer 5: 591-602, 2005.

4. Paridaens R, Biganzoli L, Bruning P, Klijn JG, Gamucci T, Houston S, Coleman R, Schachter J, Van Vreckem A, Sylvester R, Awada A, Wildiers J and Piccart M: Paclitaxel versus doxorubicin as first-line single-agent chemotherapy for metastatic breast cancer: a European Organization for Research and Treatment of cancer randomized study with cross-over. J Clin Oncol 18: 724-733, 2000.

5. Garcia-Carbonero R and Supko JG: Current perspectives on the clinical experience, pharmacology, and continued development of the camptothecins. Clin Cancer Res 8: 641-661, 2002.

6. Galano G, Caputo M, Tecce MF and Capasso A: Efficacy and tolerability of vinorelbine in the cancer therapy. Curr Drug Saf 6: 185-193, 2011.

7. Kobayashi Y, Nakano Y, Kizaki M, Hoshikuma K, Yokoo Y and Kamiya T: Capsaicin-like anti-obese activities of evodiamine from fruits of Evodia rutaecarpa, a vanilloid receptor agonist. Planta Med 67: 628-633, 2001.

8. Dai JP, Li WZ, Zhao XF, Wang GF, Yang JC, Zhang L, Chen XX, $\mathrm{Xu}$ YX and Li KS: A drug screening method based on the autophagy pathway and studies of the mechanism of evodiamine against influenza A virus. PLoS One 7: e42706, 2012. 
9. Rang WQ, Du YH, Hu CP, Ye F, Xu KP, Peng J, Deng HW and Li YJ: Protective effects of evodiamine on myocardial ischemiareperfusion injury in rats. Planta Med 70: 1140-1143, 2004.

10. Lin H, Tsai SC, Chen JJ, Chiao YC, Wang SW, Wang GJ, Chen CF and Wang PS: Effects of evodiamine on the secretion of testosterone in rat testicular interstitial cells. Metabolism 48: $1532-1535,1999$.

11. Zhang C, Fan X, Xu X, Yang X, Wang X and Liang HP: Evodiamine induces caspase-dependent apoptosis and $\mathrm{S}$ phase arrest in human colon lovo cells. Anticancer Drugs 21: 766-776, 2010.

12. Kan SF, Huang WJ, Lin LC and Wang PS: Inhibitory effects of evodiamine on the growth of human prostate cancer cell line LNCaP. Int J Cancer 110: 641-651, 2004.

13. Chen MC, Yu CH, Wang SW, Pu HF, Kan SF, Lin LC, Chi CW, Ho LL, Lee $\mathrm{CH}$ and Wang PS: Anti-proliferative effects of evodiamine on human thyroid cancer cell line ARO. J Cell Biochem 110: 1495-1503, 2010.

14. Yang ZG, Chen AQ and Liu B: Antiproliferation and apoptosis induced by evodiamine in human colorectal carcinoma cells (COLO-205). Chem Biodivers 6: 924-933, 2009.

15. Ogasawara M, Matsubara T and Suzuki H: Screening of natural compounds for Inhibitory activity on colon cancer cell migration. Biol Pharm Bull 24: 720-723, 2001.

16. Ogasawara M, Matsunaga T, Takahashi S, Saiki I and Suzuki H: Anti-invasive and metastatic activities of evodiamine. Biol Pharm Bull 25: 1491-1493, 2002.

17. Ogasawara M, Matsubara T and Suzuki H: Inhibitory effects of evodiamine on in vitro invasion and experimental lung metastasis of murine colon cancer cells. Biol Pharm Bull 24: 917-920, 2001.

18. Takada Y, Kobayashi Y and Aggarwal BB: Evodiamine abolishes constitutive and inducible NF- $\kappa \mathrm{B}$ activation by inhibiting

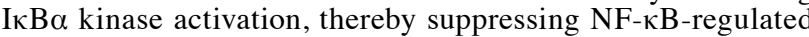
antiapoptotic and metastatic gene expression, up-regulating apoptosis, and inhibiting invasion. J Biol Chem 280: 17203-17212, 2005.

19. Zhou WH, Du MR, Dong L, Zhu XY, Yang JY, He YY and Li DJ: Cyclosporin A increases expression of matrix metalloproteinase 9 and 2 and invasiveness in vitro of the first-trimester human trophoblast cells via the mitogen-activated protein kinase pathway. Hum Reprod 22: 2743-2750, 2007.

20. Köhrmann A, Kammerer U, Kapp M, Dietl J and Anacker J: Expression of matrix metalloproteinases (MMPs) in primary human breast cancer and breast cancer cell lines: new findings and review of the literature. BMC Cancer 9: 188, 2009.

21. Ulisse S, Baldini E, Sorrenti S and D'Armiento M: The urokinase plasminogen activator system: a target for anti-cancer therapy. Curr Cancer Drug Targets 9: 32-71, 2009.

22. Han B, Nakamura M, Mori I, Nakamura Y and Kakudo K: Urokinase-type plasminogen activator system and breast cancer (Review). Oncol Rep 14: 105-112, 2005.

23. Malumbres $M$ and Barbacid M: Cell cycle, CDKs and cancer: changing paradigm. Nat Rev Cancer 9: 153-166, 2009.
24. Hunter T and Pines J: Cyclins and cancer. II: cyclin D and CDK inhibitors come of age. Cell 79: 573-582, 1994.

25. Zhang Y, Zhang QH, Wu LJ, Tashiro S, Onodera S and Ikejima T: Atypical apoptosis in L929 cells induced by evodiamine isolated from Evodia rutaecarpa. J Asian Nat Prod Res 6: 19-27, 2004.

26. Korsmeyer SJ, Shutter JR, Veis DJ, Merry DE and Oltvai ZN: Bcl-2/Bax: a rheostat that regulates an anti-oxidant pathway and cell death. Semin Cancer Biol 4: 327-332, 1993.

27. Wu GS: Role of mitogen-activated protein kinase phosphatases (MKPs) in cancer. Cancer Metastasis Rev 26: 579-585, 2007.

28. Reddy KB, Nabha SM and Atanaskova N: Role of MAP kinase in tumor progression and invasion. Cancer Metastasis Rev 22: 395-403, 2003

29. Dhillon AS, Hagan S, Rath O and Kolch W: MAP kinase signalling pathways in cancer. Oncogene 26: 3279-3290, 2007.

30. Seddighzadeh M, Zhou JN, Kronenwett U, Shoshan MC, Auer G, Sten-Linder M, Wiman B and Linder S: ERK signalling in metastatic human MDA-MB-231 breast carcinoma cells is adapted to obtain high urokinase expression and rapid cell proliferation. Clin Exp Metastasis 17: 649-654, 1999.

31. You J, Mi D, Zhou X, Qiao L, Zhang H, Zhang X and Ye L: A positive feedback between activated extracellularly regulated kinase and cyclooxygenase/lipoxygenase maintains proliferation and migration of breast cancer cells. Endocrinology 150 $1607-1617,2009$.

32. Li T, Feng Z, Jia S, Wang W, Du Z, Chen N and Chen Z: Daintain/AIF-1 promotes breast cancer cell migration by up-regulated TNF- $\alpha$ via activate p38 MAPK signaling pathway. Breast Cancer Res Treat 131: 891-898, 2012.

33. Xia Z, Dickens M, Raingeaud J, Davis RJ and Greenberg ME: Opposing effects of ERK and JNK-p38 MAP kinases on apoptosis. Science 270: 1326-1331, 1995.

34. Zhang Y, Zhang QH, Wu LJ, Tashiro Shin-Ichi, Satoshi O and Takashi I: Regulation of ERK MAPK in evodiamine-induced A375-S2 cell death. Chin J Pathophysiol 20: 2175-2179, 2004.

35. Zelivianski S, Spellman M, Kellerman M, Kakitelashvilli V, Zhou XW, Lugo E, Lee MS, Taylor R, Davis TL, Hauke R and Lin MF: ERK inhibitor PD98059 enhances docetaxel-induced apoptosis of androgen-independent human prostate cancer cells. Int J Cancer 107: 478-485, 2003.

36. Fiddes RJ, Janes PW, Sivertsen SP, Sutherland RL, Musgrove EA and Daly RJ: Inhibition of the MAP kinase cascade blocks heregulin-induced cell cycle progression in T-47D human breast cancer cells. Oncogene 16: 2803-2813, 1998.

37. Boldt S, Weidle UH and Kolch W: The role of MAPK pathways in the action of chemotherapeutic drugs. Carcinogenesis 23: 1831-1838, 2002.

38. Porras A, Zuluaga S, Black E, Valladares A, Alvarez AM, Ambrosino C, Benito M and Nebreda AR: P38 $\alpha$ mitogenactivated protein kinase sensitizes cells to apoptosis induced by different stimuli. Mol Biol Cell 15: 922-933, 2004. 